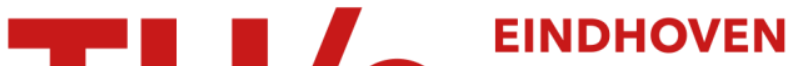 UNIVERSITY OF TECHNOLOGY
}

\section{Probabilistic model for fatigue crack growth and fracture of welded joints in civil engineering structures}

\section{Citation for published version (APA):}

Maljaars, J., Steenbergen, H. M. G. M., \& Vrouwenvelder, A. C. W. M. (2012). Probabilistic model for fatigue crack growth and fracture of welded joints in civil engineering structures. International Journal of Fatigue, 38, 108-117. https://doi.org/10.1016/j.ijfatigue.2011.11.008

DOI:

10.1016/j.ijfatigue.2011.11.008

Document status and date:

Published: 01/01/2012

\section{Document Version:}

Publisher's PDF, also known as Version of Record (includes final page, issue and volume numbers)

\section{Please check the document version of this publication:}

- A submitted manuscript is the version of the article upon submission and before peer-review. There can be important differences between the submitted version and the official published version of record. People interested in the research are advised to contact the author for the final version of the publication, or visit the $\mathrm{DOI}$ to the publisher's website.

- The final author version and the galley proof are versions of the publication after peer review.

- The final published version features the final layout of the paper including the volume, issue and page numbers.

Link to publication

\section{General rights}

Copyright and moral rights for the publications made accessible in the public portal are retained by the authors and/or other copyright owners and it is a condition of accessing publications that users recognise and abide by the legal requirements associated with these rights.

- Users may download and print one copy of any publication from the public portal for the purpose of private study or research.

- You may not further distribute the material or use it for any profit-making activity or commercial gain

- You may freely distribute the URL identifying the publication in the public portal.

If the publication is distributed under the terms of Article 25fa of the Dutch Copyright Act, indicated by the "Taverne" license above, please follow below link for the End User Agreement:

www.tue.nl/taverne

Take down policy

If you believe that this document breaches copyright please contact us at:

openaccess@tue.nl

providing details and we will investigate your claim. 


\title{
Probabilistic model for fatigue crack growth and fracture of welded joints in civil engineering structures
}

\author{
J. Maljaars ${ }^{a, *}$, H.M.G.M. Steenbergen ${ }^{a}$, A.C.W.M. Vrouwenvelder ${ }^{a, b}$ \\ a TNO, P.O. Box 49, 2600 AA Delft, The Netherlands \\ ${ }^{\mathrm{b}}$ Delft University of Technology, Faculty of Civil Engineering and Geosciences, P.O. Box 5, 2600 AA Delft, The Netherlands
}

\section{A R T I C L E I N F O}

\section{Article history:}

Received 26 April 2011

Received in revised form 19 November 2011

Accepted 24 November 2011

Available online 9 December 2011

\section{Keywords:}

Fatigue life prediction

Probability of failure

Partial factors

Linear elastic fracture mechanics (LEFM)

Bridge details

\begin{abstract}
A B S T R A C T
This paper presents a probabilistic assessment model for linear elastic fracture mechanics (LEFM). The model allows the determination of the failure probability of a structure subjected to fatigue loading. The distributions of the random variables for civil engineering structures are provided, and the relative importance of these random variables is determined. An example of a bridge detail is provided in order to show the application of the model. Partial factors are derived for the case of fatigue of welded joints in civil engineering structures. The failure probability appears to be relatively insensitive to the failure criterion (attainment of a through-thickness crack or fracture) when considering the total fatigue life.
\end{abstract}

(c) 2011 Elsevier Ltd. All rights reserved.

\section{Introduction}

Since its introduction by Irwin and its application to fatigue by Paris, linear elastic fracture mechanics (LEFM) is a widespread technique used to determine the (residual) life of a structure or component subjected to fluctuating stresses. The method is provided in standards $[1,2]$ and others. In most design procedures, a deterministic approach is applied where the mean value or the mean minus or plus a number of standard deviations is used for the variables such as the crack dimensions and the fatigue crack growth curve. Partial factors are introduced in order to arrive at the required reliability level. These factors are sometimes estimated based on practical experience from the past, or best-guess value are applied. Due to this procedure, the value of the reliability index $\beta$ in LEFM is unknown in many cases.

Burkedin and Hamour $[3,4]$ have derived partial factors for fracture associated with certain values of $\beta$. These partial factors have been incorporated in [1]. However, the standard does not provide partial factors for fatigue. In many other standards for fatigue notably standards based on $S-N$ curves such as the EN 1993 series $[5,6]$ - the relationship between failure and fracture is not explicitly accounted for, other than providing a minimum Charpy value or a maximum thickness value. This raises the question as to

\footnotetext{
* Corresponding author. Tel.: +31 888663464 .

E-mail address: johan.maljaars@tno.nl (J. Maljaars).
}

whether or not the fracture characteristics have a significant influence on the failure probability of a fatigue loaded structure.

Various studies into probabilistic fatigue assessment using LEFM have been conducted. The effects of uncertainties in loading, initial crack width and other factors were assessed in [7]. Probabilistic LEFM was applied to determine the inspection interval of cover plates in bridges in the USA in [8]. A comprehensive overview of more recent probabilistic fatigue assessment models for welded steel structures is provided in [9]. One study, [10], is of special interest, in that it gives a complete overview of the influence of almost all relevant random variables on the failure probability. However, the study is dedicated to stress analysis by measurements for a detail in a specific bridge, so uncertainty factors in models for determining stresses were not considered. Other important differences are the choice of the stress ranges (constant, equivalent range in [10] versus variable amplitude loading in this paper) and the application of statistical methods within the model (used to determine the relative importance of variables in [10] versus used to derive partial factors in this paper).

The study reported in this paper is a follow-up of the earlier probabilistic LEFM studies for fatigue and fatigue followed by fracture. Contrarily to the previous models - the model in [10] as well as all other models described in [9] - it considers the fact that a large stress cycle that can cause fracture, can occur at any moment in time. Thus, the failure probability of the fatigue loaded structure is a combination of the failure probabilities for all time intervals. The LEFM model is based on BS 7910 [1]. For practical 


\begin{tabular}{|c|c|c|c|}
\hline \multicolumn{4}{|c|}{ Nomenclature } \\
\hline$a$ & depth of a semi-elliptical crack [mm] & $\mu$ & mean value \\
\hline$c$ & $\begin{array}{l}\text { half-width at the plate surface of a semi-elliptical crack } \\
{[\mathrm{mm}]}\end{array}$ & $\sigma$ & $\begin{array}{l}\text { stress, including stress concentrations due to the joint } \\
\text { geometry }\left[\mathrm{N} / \mathrm{mm}^{2}\right]\end{array}$ \\
\hline$f(\cdot)$ & probability density function $[-]$ & $\sigma_{y}$ & yield stress $\left[\mathrm{N} / \mathrm{mm}^{2}\right]$ \\
\hline$g(\cdot)$ & limit state function $[-]$ & $\sigma_{u}$ & ultimate tensile strength $\left[\mathrm{N} / \mathrm{mm}^{2}\right]$ \\
\hline$m$ & Paris Law exponent $[-]$ & $\sigma_{r}$ & standard deviation of the stress process $\left[\mathrm{N} / \mathrm{mm}^{2}\right]$ \\
\hline$p$ & thickness exponent $[-]$ & $\lambda$ & Weibull shape parameter $\left[\mathrm{N} / \mathrm{mm}^{2}\right]$ \\
\hline$t$ & time $[s]$ & $\rho$ & plasticity correction factor or correlation coefficient [-] \\
\hline$u, v, w$ & $\begin{array}{l}\text { independent standard Gauss variables, representing the } \\
\text { physical variables } X \text { in a FORM analysis }\end{array}$ & $\phi$ & $\begin{array}{l}\text { Cumulative distribution function of the standardised } \\
\text { Gauss distribution [-] }\end{array}$ \\
\hline$A$ & Paris Law parameter $(\mathrm{N}, \mathrm{mm})$ & $\Delta$ & range operator $[-]$ \\
\hline$B$ & plate thickness [mm] & & \\
\hline$C$ & model uncertainty $[-]$ & \multicolumn{2}{|c|}{ Subscripts } \\
\hline$E[]$ & expectation operator [-] & 0 & threshold value \\
\hline$F()$ & cumulative distribution function $[-]$ & $a$ & in depth direction of a semi-elliptical crack \\
\hline$K$ & elastic stress intensity factor $\left[\mathrm{N} / \mathrm{mm}^{3 / 2}\right]$ & $b$ & bending \\
\hline$K_{\text {mat }}$ & material fracture toughness $\left[\mathrm{N} / \mathrm{mm}^{3 / 2}\right]$ & $c$ & in width direction of a semi-elliptical crack \\
\hline$K_{r}$ & fracture ratio $[-]$ & $d$ & design value \\
\hline$L$ & node length [mm] & $\mathrm{cr}$ & critical value \\
\hline$L_{r}$ & plastic collapse ratio [-] & $f$ & failure value \\
\hline$N$ & number of stress cycles [-] & glob & global stress analysis \\
\hline$P$ & probability [-] & $k$ & interval operator or characteristic value \\
\hline$R$ & failure resistance $[-]$ & $m$ & membrane \\
\hline$T$ & operating temperature $\left[{ }^{\circ} \mathrm{C}\right]$ & nom & nominal value \\
\hline$T_{0}$ & temperature for a median toughness of $3162 \mathrm{~N} / \mathrm{mm}^{3 / 2}$ & 0 & initial value \\
\hline & or $100 \mathrm{MPa} \mathrm{m}^{1 / 2}\left[{ }^{\circ} \mathrm{C}\right]$ & $p$ & primary (primary stresses are stresses that could con- \\
\hline$T_{k}$ & temperature term that describes the scatter in the Char- & & tribute to plastic collapse) \\
\hline & py versus fracture toughness correlation $\left[{ }^{\circ} \mathrm{C}\right]$ & ref & reference value \\
\hline$V$ & coefficient of variation $[-]$ & res & residual \\
\hline$W$ & plate width $[\mathrm{mm}]$ & $s$ & secondary (secondary stresses are self-equilibrating \\
\hline$X$ & random variable vector $[-]$ & & stresses necessary to satisfy compatibility) \\
\hline Y & stress intensity correction factor $[-]$ & $s c f$ & stress concentration factor \\
\hline$\alpha$ & FORM sensitivity factor [-] & sif & stress intensity factor \\
\hline$\beta$ & reliability index $[-]$ & $t r$ & transition value \\
\hline$\gamma_{f a t}$ & partial factor for fatigue [-] & $I$ & tension (mode I) \\
\hline
\end{tabular}

purposes, partial factors are derived with the model for welded joints in civil engineering steel structures with the following characteristics:

- The spectrum of highway traffic loads, railway traffic loads, wind loads and wave loads can usually be approximated by a Weibull or closely related distribution - refer to [11-14], respectively. Thus, the fluctuating stress spectrum is approximated as a Weibull distribution.

- The fluctuating stresses are randomly distributed.

- The fluctuating part of the stress is relatively large: its characteristic value is at least of the same magnitude as the permanent stress, e.g. due to the self-weight [15].

- Post welding treatments are not applied.

- Only Charpy-V values are available to assess the material properties for fracture.

- The temperature difference between the minimum operating temperature and the Charpy transition temperature at $27 \mathrm{~J}$ is sufficiently large, so that the structure is in the transition range or upper-shelf range.

The existing deterministic model for fatigue in [1] is briefly presented in Section 2.1, and the applied fracture criterion is presented in Section 2.2. After that, the probabilistic theoretical model and the distribution functions for all relevant random variables are presented, Section 3. The application of the model is illustrated by an example, Section 4. Partial factors are derived in Section 5.

\section{Deterministic model in BS 7910}

\subsection{Fatigue crack growth model}

The stress intensity factor $K$ for a certain applied stress $\sigma$ is given as

$K=\sigma Y \sqrt{\pi a}=\left(\sigma_{m} Y_{m}+\sigma_{b} Y_{b}\right) \sqrt{\pi a}$

The membrane and bending stress components, $\sigma_{m}$ and $\sigma_{b}$, are determined from the applied loading at the crack location. They include the stress concentration resulting from the global geometry of the joint but do not include the stress concentration due to the crack or the geometry of the weld. The influence of the crack, plate and weld geometry are included in the stress intensity correction factors $Y$, which can be determined with the finite element (FE) method for any geometry. Various reference books provide equations that give an approximation of $Y$ for standard details, such as [16]. In this paper, the equations in [1] are used for $Y$. In the case of a semi-elliptical surface crack, the crack shape is characterised by two variables, being the depth, $a$, and the half-width at the surface, $c$ (Fig. 1).

For each principal direction of crack growth, a Paris type expression may be formulated

$\frac{d a}{d N}=A\left(\Delta K_{a}\right)^{m}$ for $\quad \Delta K_{a}>\Delta K_{0}$ $\frac{d c}{d N}=A\left(\Delta K_{c}\right)^{m}$ for $\quad \Delta K_{c}>\Delta K_{0}$ 


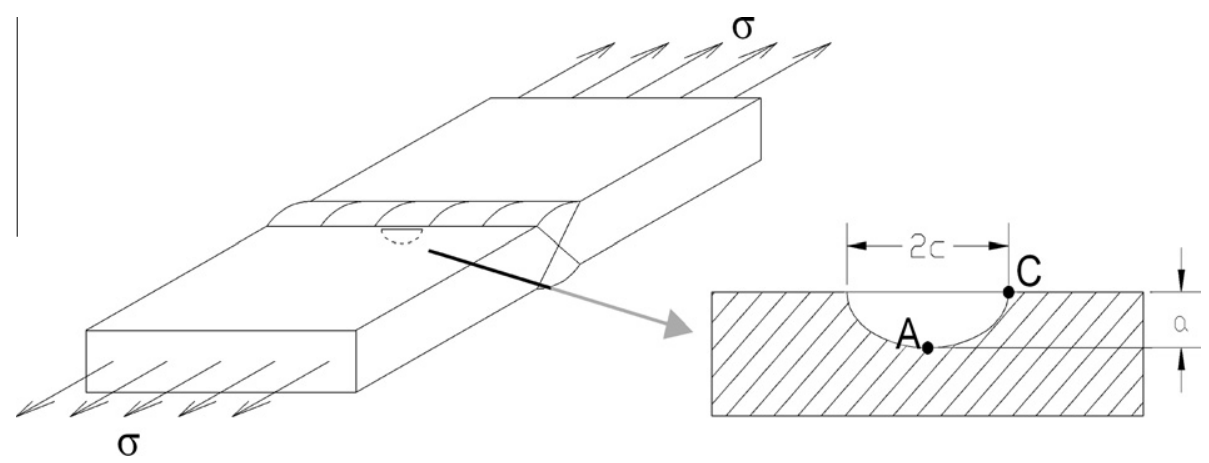

Fig. 1. A semi-elliptical crack in a steel plate at/near the weld toe.

where the first expression relates to point $A$ and growth in the depth direction. The second expression relates to point $C$ and growth in the width direction (Fig. 1). The stress intensity factor ranges $\Delta K_{a}$ and $\Delta K_{c}$ are given by

$$
\begin{aligned}
& \Delta K_{a}=\left(\Delta \sigma_{m} Y_{m a}+\Delta \sigma_{b} Y_{b a}\right) \sqrt{\pi a} \\
& \Delta K_{c}=\left(\Delta \sigma_{m} Y_{m c}+\Delta \sigma_{b} Y_{b c}\right) \sqrt{\pi a}
\end{aligned}
$$

where $\Delta \sigma$ is the applied stress range, and $Y_{a}$ and $Y_{c}$ are stress intensity correction factors for points $A$ and $C$, respectively. The bi-linear version of the fatigue crack growth model by Paris and Erdogan [17] is considered (Fig. 2).

$$
\frac{d a}{d N}=\left\{\begin{array}{lll}
0 & \text { for } & \Delta K \leqslant \Delta K_{0} \\
A_{1}(\Delta K)^{m_{1}} & \text { for } & \Delta K_{0}<\Delta K \leqslant \Delta K_{t r} \\
A_{2}(\Delta K)^{m_{2}} & \text { for } & \Delta K>\Delta K_{t r}
\end{array}\right.
$$

A pair of coupled differential equations is obtained by substitution of Eq. (3) in Eq. (2). With the exception of the material parameters $(A, m)$ and the applied stress range $\Delta \sigma$, all other terms are a function of the crack size $(a, c)$. The equations are evaluated through an incremental numerical procedure, resulting in the relationships between the number of cycles, $N$, and the crack dimensions, $a$ and $c$. Starting values are the initial defect dimensions, $a_{o}$ and $c_{o}$, and the number of cycles up to crack initiation, $N_{o}$. Since $N_{o}$ is usually small for welded connections, its value is set to 0 in this paper.

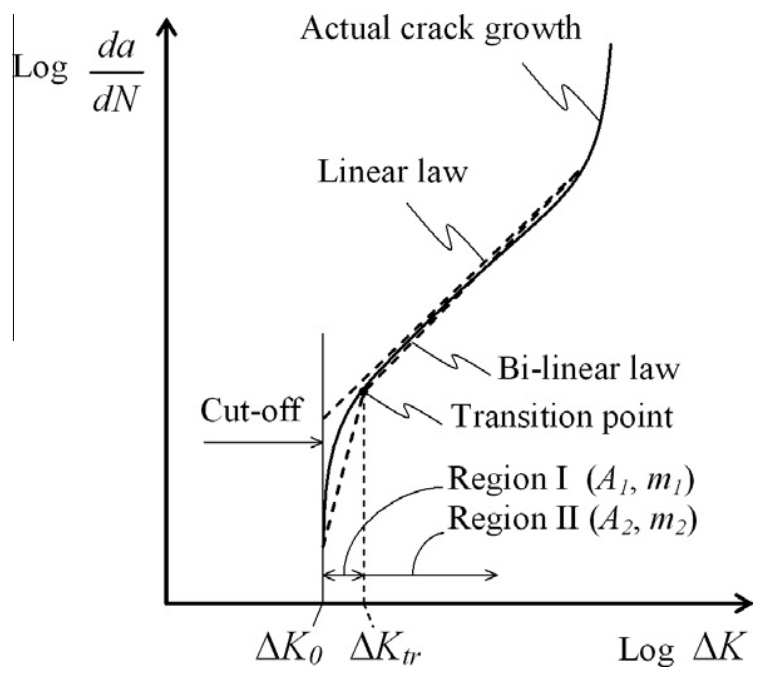

Fig. 2. Schematic representation of typical crack growth rates with linear and bilinear approximations.

\subsection{Fracture model}

In some cases - notably pipelines - failure may be associated with the attainment of a through-thickness crack. In other cases, it is associated with the integrity of the cross-section. In the latter cases, failure occurs when a load cycle exceeds the load bearing capacity of the remaining ligament. This remaining load bearing capacity depends on the actual crack size and the interaction between plastic collapse and fracture. The maximum crack depth that can be sustained by the component is called the critical crack depth, $a_{c r}$, and it depends on the material's yield stress and fracture toughness, $K_{\text {mat }}$. Several alternatives for the failure assessment curve are provided in [1]. The equations representing the failure assessment line of the often applied method $2 \mathrm{~A}$ in [1] can be formulated as:

$$
K_{r f}= \begin{cases}0 & \text { for } L_{r}>L_{r \max } \\ \left(1-0.14 L_{r}^{2}\right)\left(0.3+0.7 \exp \left(-0.65 L_{r}^{6}\right)\right) & \text { for } L_{r} \leqslant L_{r \max }\end{cases}
$$

An alternative for Eq. (5) based on the results of large-scale tests is provided by [18]:

$K_{r, f}=\sqrt{R^{2}-L_{r}^{2}}$

Failure is expected when a load cycle causes $K_{r}>K_{r, f}$. Fig. 3 presents both failure assessment diagrams together with the results of large-scale tests.

Variable $R$ is a normalised resistance parameter, usually taken as 1.0 in deterministic design calculations. Fig. 3 shows that 1.0 is a safe value in most cases, and the mean value is 1.7. Quantities $K_{r}, L_{r}$ and $L_{r, \max }$ are defined as follows:

$K_{r}=\frac{K_{I}}{K_{\text {mat }}}+\rho \quad$ and $\quad L_{r}=\frac{\sigma_{r e f}}{\sigma_{y}} \quad$ and $\quad L_{r, \max }=\frac{\sigma_{y}+\sigma_{u}}{2 \sigma_{y}}$

where $K_{m a t}$ is the material toughness measured by stress intensity factor (Eq. (8)); $K_{I}$ is the stress intensity factor: $K_{I}=\left(Y_{p} \sigma_{p}+Y_{s} \sigma_{s}\right) \sqrt{\pi a} ; \rho$ is the plasticity correction factor (refer to [1]); and $\sigma_{r e f}$ is the reference stress, which is a function of the primary stress $\sigma_{p}$ (refer to [1])

In the absence of crack tip opening displacement (CTOD) or $J$ integral tests, the material thoughness, $K_{m a t}$, may be estimated from Charpy $\mathrm{V}$ tests (units $\mathrm{N}, \mathrm{mm}$ and ${ }^{\circ} \mathrm{C}$ ):

$K_{\text {mat }}=632+\left[348+2435 \cdot \exp \left(\frac{T-T_{0}-T_{k}}{52}\right)\right]\left(\frac{25}{B}\right)^{1 / 4}\left[\ln \left(\frac{1}{1-P}\right)\right]^{1 / 4}$

where $T$ is the operating temperature, $T_{0}$ is the temperature for a median toughness of $3162 \mathrm{~N} / \mathrm{mm}^{3 / 2}$, or $100 \mathrm{MPa} \mathrm{m}{ }^{1 / 2}$, (which is taken equal to $T_{27 \mathrm{~J}}-18^{\circ} \mathrm{C}$, where $T_{27 \mathrm{~J}}$ is the Charpy transition temper- 


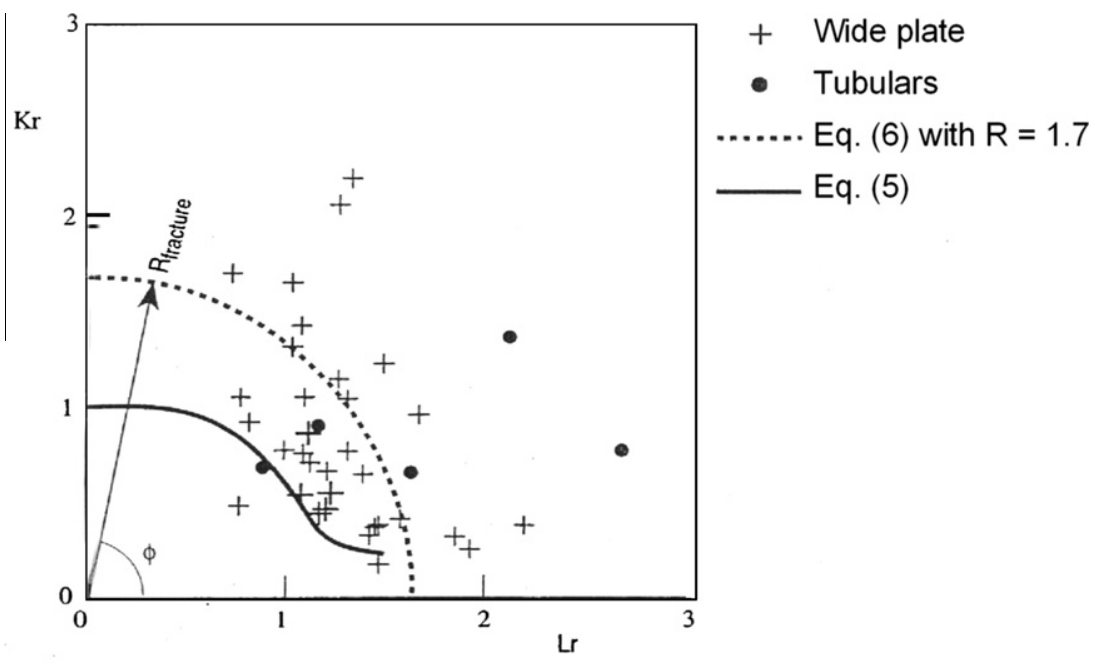

Fig. 3. $K_{r}-L_{r}$ interaction curves according to [1] (Eq. (5)) and [18] (Eq. (6)), with test failure data on mild steel large scale specimens from [18].

ature at $27 \mathrm{~J}), T_{k}$ is the temperature term that describes the scatter in the Charpy versus fracture toughness correlation (which is $25^{\circ} \mathrm{C}$ for a standard deviation of $15{ }^{\circ} \mathrm{C}$ and $90 \%$ confidence level) and $P$ is the probability of $K_{m a t}$ being less than estimated (BS 7910 recommends the use of $P=0.05$ in the absence of experiments that prove otherwise).

\section{Probabilistic LEFM model}

\subsection{Fatigue crack growth}

The stress ranges are randomly distributed. Assuming that for $\Delta \sigma$, a sufficiently mixing (ergodic) process, we may use the expectation of the stress range to find the expectation of $d a / d N$

$$
\begin{aligned}
E\left(\frac{d a}{d N}\right)= & A_{1} E\left[\Delta \sigma^{m_{1}}\right]_{\Delta \sigma_{\text {th }}}^{\Delta \sigma_{\text {tr }}} \cdot\left(\left[\frac{B_{\text {nom }}}{B}\right]^{p} C_{\text {load }} C_{\text {glob }} C_{\text {scf }} C_{\text {sif }} Y_{a} \sqrt{\pi a}\right)^{m_{1}} \ldots \\
& +A_{2} E\left[\Delta \sigma^{m_{2}}\right]_{\Delta \sigma_{\text {tr }}}^{\infty} \cdot\left(\left[\frac{B_{\text {nom }}}{B}\right]^{p} C_{\text {load }} C_{\text {glob }} C_{\text {scf }} C_{\text {sif }} Y_{a} \sqrt{\pi a}\right)^{m_{2}}
\end{aligned}
$$

and

$$
E\left[\Delta \sigma^{m}\right]_{s_{1}}^{s_{2}}=\int_{s_{1}}^{s_{2}} s^{m} f_{\Delta \sigma}(s) d s
$$

For the crack width evaluation (direction $c$ ), a similar equation as Eq. (9) is applied. The factors $C$ represent model uncertainties for the fluctuating load model and for various stress calculations (loading, stress analysis of the entire structure, e.g. by the FE model, stress concentration factor and stress intensity factor), and $f \Delta \sigma(s)$ is the probability density function of the stress ranges, $\Delta \sigma$. The parameter $B_{\text {nom }}$ is the plate thickness applied in the calculation of the stress - usually taken as the average plate thickness. Thickness exponent $p$ addresses the dependency of the stress on the plate thickness. Its value depends on the type of loading. For bending stress, $p$ is equal to 2 . For membrane stress, $p$ ranges between 0 and 1 - depending on the geometry - and is often close to 1 . As an example, $p$ is equal to 1 in the case of a single plate in tension, and $p$ is approximately 0.8 in the case of a flange of an I section loaded in bending. Other overall dimensions such as the plate width are considered deterministic because the variation in these other overall dimensions is usually small compared to the variation in plate thickness.

Eq. (10) can be solved numerically using small stress range steps, $s$. Alternatively, the expectation of the $m$ th moment of the stress distribution, Eq. (10), can be derived directly depending on the stress spectrum. Three options are detailed here:

1. If the stress process is Gaussian and has a narrow banded spectrum, it can be shown that the peaks of the stress process - and hence the stress ranges - follow a Rayleigh distribution. For this case, the $m$ th moment of the stress range density function can be obtained as

$E\left[\Delta \sigma^{m}\right]=\left(2 \sigma_{r} \sqrt{2}\right)^{m} \Gamma\left(\frac{m}{2}+1\right)$

where $\sigma_{r}$ is the standard deviation of the Gaussian stress process, and $\Gamma(\cdot)$ is the Gamma function. For a crack growth curve consisting of two slopes Eq. (11) is replaced by:

$$
\begin{aligned}
& E\left[\Delta \sigma^{m}\right]_{\sigma_{t h}}^{\sigma_{t r}}=\left(2 \sigma_{r} \sqrt{2}\right)^{m 1} \Gamma\left(\frac{m_{1}}{2}+1 ; \quad\left(\frac{\sigma_{t r}}{2 \sigma_{r} \sqrt{2}}\right)^{2}\right) \\
& E\left[\Delta \sigma^{m}\right]_{\sigma_{t r}}^{\infty}=\left(2 \sigma_{r} \sqrt{2}\right)^{m 2} \Gamma_{0}\left(\frac{m_{2}}{2}+1 ; \quad\left(\frac{\sigma_{t r}}{2 \sigma_{r} \sqrt{2}}\right)^{2}\right)
\end{aligned}
$$

where $\Gamma(a ; b)$ denotes the incomplete Gamma function and $\Gamma_{0}(a ; b)=\Gamma(a)-\Gamma(a ; b)$ the complementary Gamma function.

2 . If the stress has a narrow banded spectrum and the peaks follow a Weibull distribution

$F_{\Delta \sigma}(s)=1-\exp \left(-\left(\frac{s}{\sigma_{r}}\right)^{\lambda}\right)$

the $m$ th moment of the stress range density function is equal to

$E\left[\Delta \sigma^{m}\right]=\sigma_{r}^{m} \Gamma\left(\frac{m}{\lambda}+1\right)$

and for two slopes

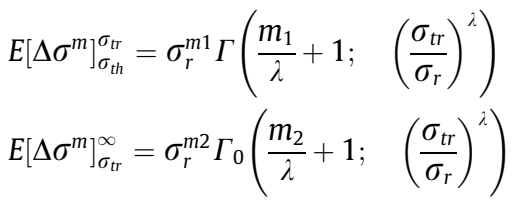

Note that a Weibull distribution with $\lambda=2$ is equal to the Rayleigh distribution. 
3. If the stress spectrum is broad-banded, the stress cycles cannot be easily distinguished. In this case, a convention is required for defining stress cycles. There are two approaches available for the modelling of stress cycles of a broad-banded stress process:

- Cycle counting methods. The time history of the stress process can be summarised using rain flow counting [19]. In the case of a crack growth curve with one slope, the stress expectations are equal to:

$$
E\left[\Delta \sigma^{m}\right]=\sum_{i}\left(\frac{N_{\mathrm{i}}}{\sum_{i} N_{\mathrm{i}}}\left(\Delta \sigma_{i}^{m}\right)\right)
$$

where $N_{i}$ is the number of cycles corresponding to rain flow stress range $\Delta \sigma_{i}$ and $N_{i}$ is the total number of cycles. For a two-slope crack growth curve, Eq. (10) may be used.

- Empirically derived semi-analytical probability distributions for stress ranges of a wide banded stress process such as the 5parameter mixed Weibull distribution by Zhao and Baker [20].

\subsection{Limit state function}

Two limit state functions are detailed here:

- $g_{1}$ : Failure is associated with the attainment of a certain crack depth, e.g. a through-thickness crack.

$-g_{2}$ : Failure is associated with fracture.

The limit state function for failure associated with a critical crack depth $a_{c r}$ can be formulated as

$g_{1}(X, t)=a_{c r}-a(t)$

or, alternatively,

$g_{1}(X, t)=N_{c r}-N(t)$

where $N$ is the number of cycles at time $t$, corresponding with a crack depth $a . N_{c r}$ is the number of cycles up to the attainment of the critical crack depth $a_{c r}$. For calculation purposes, the crack depth increase may be divided into, e.g. 1000 intervals $k: \Delta a_{k}=\left(a_{c r}-a_{0}\right) /$ 1000. For every crack depth interval $\Delta a_{k}$, the number of cycles, $\Delta N_{c r, k}$, and the crack width interval, $\Delta c_{k}$, are determined. Summation of $\Delta N_{c r, k}$ gives $N_{c r}$. The failure probability is denoted as

$P_{f}=P\left[g_{1}(X, t) \leqslant 0\right]$

and it can be calculated directly using a Monte Carlo analysis, a First Order Reliability Method (FORM) or other suitable techniques.

In case failure is associated with fracture, the limit state function may be formulated as:

$g_{2}(X, t)=R^{2}-K_{r}^{2}-L_{r}^{2}$

Or, alternatively,

$g_{2}(X, t)=N_{f}-N(t)$

where $N_{f}$ is the number of cycles at fracture, i.e. when $R^{2}=K_{r}^{2}+L_{r}^{2}$. Parameter $K_{r}$ depends on $K_{I}$ and $K_{\text {mat }}$ (Eq. (7)). The value of $K_{I}$ is determined in each interval $k$

$K_{I, k}=\sigma_{p k} \cdot\left[\frac{B_{\text {nom }}}{B}\right]^{p} C_{\text {load }} C_{\text {glob }} C_{s c f} C_{s i f} Y_{p} \sqrt{\pi a}+\sigma_{s} \cdot C_{\text {glob }}^{*} C_{s i f} Y_{s} \sqrt{\pi a}$

where $C_{\text {glob }}^{*}$ is equal to either 1.0 or $C_{\text {glob }}$, depending on the derivation of the secondary stress. Due to the fact that the stress peaks are independent in time, the distribution function of the maximum primary stress level in interval $k$ - called $\sigma_{p k}$ - is equal to:

$F_{\sigma p k}(s)=\left[F_{\sigma p}(s)\right]^{\Delta N_{f k}}$ where $\Delta N_{f k}$ is the number of cycles calculated for interval $k$, and $F \sigma_{p}(s)$ is the cumulative distribution function of the primary stress, i.e. the sum of the permanent and the fluctuating stress.

A three-parameter Weibull distribution is proposed to describe the fracture toughness $K_{\text {mat }}$ by $[3,10]$ (units $\mathrm{N}, \mathrm{mm},{ }^{\circ} \mathrm{C}$ )

$F_{K_{\text {mat }}}(x)=1-\exp \left[-\left(\frac{x-632}{K_{m}^{*}-632}\right)^{\lambda}\right]$

$K_{m}^{*}=632+\left[348+2435 \cdot \exp \left(\frac{T-T_{0}-T_{k}}{52}\right)\right]\left(\frac{25}{B}\right)^{1 / 4}$

where $\lambda$ is the shape parameter, taken as 4 on the basis of experiments by Wallin [21].

The failure probability associated with limit state function $g_{2}$ can be approximated by one of the two following procedures:

- A lower bound of the failure probability is obtained by assuming that the maximum primary stress level, $\sigma_{p k}$, remains unaltered during crack growth. The evaluation is similar to that of limit state function $g_{1}$

- An upper bound of the failure probability is obtained by: (a) Considering $n$ time intervals for the total number of cycles $N(t)$. The number of cycles considered for crack growth in each time interval is $i \cdot N(t) / n$ with $i 1 \ldots n$. (b) Determine the crack dimensions at the end of each time interval for all $i \cdot N(t) / n$ cycles and the failure probability for the final $1 / n \cdot N(t)$ cycles of that time interval. (c) Determine the failure probability of the entire system using the method of Hohenbichler [22], in which all variables are fully correlated between the fractions except for $\sigma_{p}$, which is fully uncorrelated (refer to the Appendix A).

This upper bound approximation approaches the actual failure probability if many time intervals are considered.

The two approximations are visualised in Fig. 4. The black curve represents the stress level at the limit state. This value is decreasing due to the increasing crack growth. The grey line indicates the maximum primary stress level $\sigma_{p k}$

\subsection{Distribution functions of the random variables}

The distribution functions for the random variables in Table 1 are taken from literature. Expert opinion values are used when the distributions are not available in literature. The table also provides characteristic values $X_{k}$ that can be used in deterministic calculations.

\section{Example of a cover plate on a bridge girder}

\subsection{Description of the geometry and load model}

The example described here is a transverse weld in a cover plate detail, located in a main girder of a three span bridge as indicated in Fig. 5. The crack is growing from the weld toe into the girder flange. The part of the stress intensity correction factor, $Y$, considering the effect of the weld is taken as the 2-dimensional approximation by Maddox and Andrews, incorporated in [27,1].

The fluctuating part of the global stress $\sigma$ is modelled as a stationary zero mean Gaussian process with a standard deviation $\sigma_{r}$ (Fig. 6). The peak values $\widehat{\sigma}$ are assumed to follow a Rayleigh distribution with a mean value $\mu_{r}=\sigma_{r} \Gamma(1+1 / 2)=\sigma_{r} \sqrt{\pi / 2}=1.25 \sigma_{r}$.

$f_{\hat{\sigma}}(x)=\frac{x}{\sigma_{r}^{2}} \exp \left(-\frac{x^{2}}{2 \sigma_{r}^{2}}\right)$ 

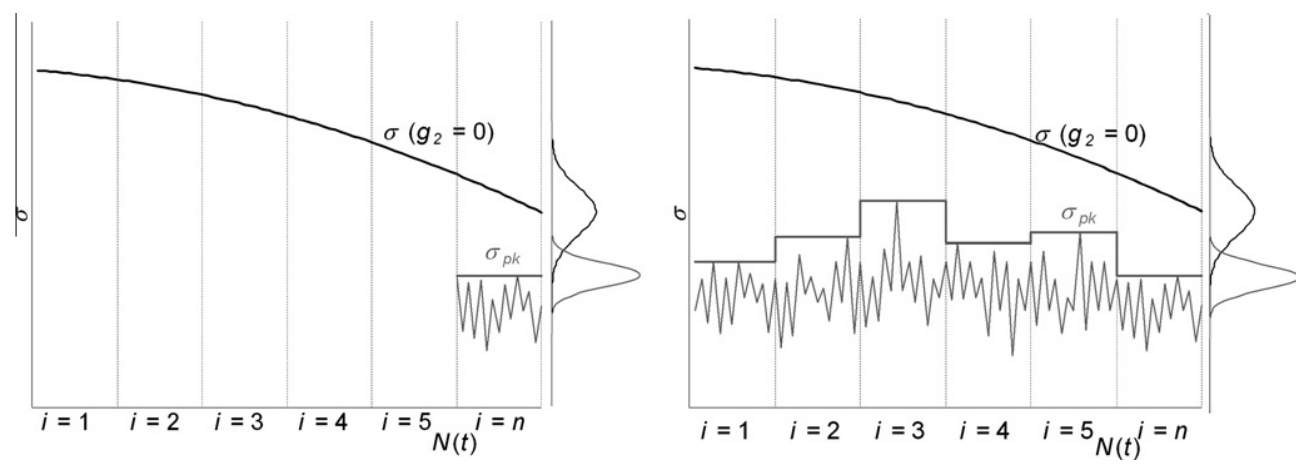

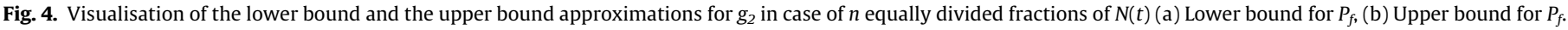

Table 1

Distribution functions for random variables (units: $\mathrm{mm}, \mathrm{N},{ }^{\circ} \mathrm{C}$ ).

\begin{tabular}{|c|c|c|c|c|c|c|}
\hline Variable & & Distribution & $\mu$ & V & Ref. & $X_{k}$ \\
\hline$A_{1}(\text { air })^{\mathrm{a}}$ & Paris Law parameter of stage I & Lognormal & $4.80 \times 10^{-18}$ & 1.70 & [1] & $\dot{\mu}(1+2 V)$ \\
\hline$A_{2}(\text { air })^{\mathrm{a}}$ & Paris Law parameter of stage II & Lognormal & $5.86 \times 10^{-13}$ & 0.60 & [1] & $\dot{\mu}(1+2 V)$ \\
\hline$m_{1}$ (air) & Slope value of stage I & Deterministic & 5.10 & - & [1] & $\mu$ \\
\hline$m_{2}$ (air) & Slope value of stage II & Deterministic & 2.88 & - & [1] & $\mu$ \\
\hline$\Delta K_{0}$ (air) & Threshold value for $\Delta K$ & Lognormal & 140 & 0.40 & [23] & $\dot{\mu}(1-2 V)$ \\
\hline$A_{1}$ (marine) $)^{\mathrm{a}}$ & Paris Law parameter of stage I & Lognormal & $5.37 \times 10^{-14}$ & 1.10 & {$[1]$} & $\dot{\mu}(1+2 V)$ \\
\hline$A_{2}$ (marine) ${ }^{\mathrm{a}}$ & Paris Law parameter of stage II & Lognormal & $5.67 \times 10^{-7}$ & 0.16 & [1] & $\dot{\mu}(1+2 V)$ \\
\hline$m_{1}$ (marine) & Slope value of stage I & Deterministic & 3.42 & - & [1] & $\mu$ \\
\hline$m_{2}$ (marine) & Slope value of stage II & Deterministic & 1.11 & - & [1] & $\mu$ \\
\hline$\Delta K_{0}$ (marine) & Threshold value for $\Delta K$ & Deterministic & 0.0 & - & [1] & $\mu$ \\
\hline$a_{o}$ & Initial crack depth ${ }^{\mathrm{d}}$ & Lognormal & 0.15 & 0.66 & {$[24,25]$} & $\mu$ \\
\hline$a_{o} / c_{o}$ & Initial aspect ratio ${ }^{\mathrm{d}}$ & Lognormal & 0.62 & 0.40 & {$[24,25]$} & $\mu$ \\
\hline$B$ & Plate thickness & Uniform & $\dot{\mu}(1 \pm 0.05)$ & & {$[26]$} & $\mu$ \\
\hline$\sigma_{\text {res }}$ & Residual stresses ${ }^{c}$ & Lognormal & 300 & 0.20 & $\mathrm{EO}^{\mathrm{f}}$ & $\mu$ \\
\hline$\sigma_{y}$ & Yield stress $^{c}$ & Lognormal & 381 & 0.07 & {$[26]$} & 355 \\
\hline$R$ & Resistance fracture toughness & Lognormal & 1.7 & 0.18 & [18] & 1 \\
\hline$K_{\text {mat }}$ & Fracture toughness & Weibull & Eqs. $(24)+(25)$ & & {$[21]$} & Eq. (8) with $P=0.05$ \\
\hline$T_{k}$ & Scatter in the Charpy versus fracture toughness correlation & Normal & 0 & $\sigma=15$ & [21] & 25 \\
\hline$C_{\text {load }}$ & MU fluctuating load model ${ }^{\mathrm{b}}$ & Lognormal & 1.0 & $-{ }^{e}$ & EO & $\mu$ \\
\hline$C_{\text {glob }}$ & MU global stress model & Lognormal & 1.0 & 0.10 & EO & $\mu$ \\
\hline$C_{s c f}$ & MU stress concentration & Lognormal & 1.0 & 0.20 & EO & $\mu$ \\
\hline$C_{\text {sif }}$ & MU stress intensity factor (hand calculation or 2D-FEM) & Lognormal & 1.0 & 0.20 & EO & $\mu$ \\
\hline$C_{\text {sif }}$ & MU stress intensity factor (3D-FEM) & Lognormal & 1.0 & 0.07 & EO & $\mu$ \\
\hline$T$ & Operating temperature & Normal & $-\mathrm{e}^{\mathrm{e}}$ & $-{ }^{\mathrm{e}}$ & & $\dot{\mu}(1-2 V)$ \\
\hline$\hat{\sigma}$ & Maximum value of the fluctuating stress & Weibull & $-e^{e}$ & $-e^{e}$ & & $\dot{\mu}(1+2 V)$ \\
\hline
\end{tabular}

a Stress ratio $\sigma_{\min } / \sigma_{\max } \geqslant 0.5$.

b $\mathrm{MU}=$ Model Uncertainty.

c Values are provided for S355.

d Values are for an as-welded structure.

e Case-dependent value.

${ }^{\mathrm{f}} \mathrm{EO}=$ Expert Opinion.

The stress ranges $\Delta \sigma$ (double amplitude) follow a Rayleigh distribution with a mean of $2.5 \sigma_{r}$. The probability density function may be written as

$f_{\Delta \sigma}(x)=\frac{x}{4 \sigma_{r}^{2}} \exp \left(-\frac{x^{2}}{8 \sigma_{r}^{2}}\right)$

The values for the case-specific parameters considered in this example are listed in Table 2.

\subsection{Fatigue life and fracture calculation}

Fig. 7 presents the crack growth and the failure assessment diagram determined with a deterministic approach. Two cases are considered: one with mean values for all random variables and one with a 'design set' of random variables, defined according to the 4 th and 7 th column of Table 1, respectively. The thick curves in the left-hand graph are valid for failure associated with fracture, and the dashed curves are valid for $a_{c r}=B$. The figure shows that the number of cycles to failure, $N_{c r}$, in case of fracture is almost equal to $N_{c r}$ of a through-thickness crack in the case of the average set of variables. For this case, the difference in $N_{c r}$ between the two failure criteria is less than $2 \%$. Thus, $N_{c r}$ appears to be insensitive to the failure criterion (either a through-thickness crack or fracture) in the case of the average set of variables. On the contrary, the figure shows that the failure criterion is important in the case of the 'design set' of variables.

The probabilistic model is programmed in Fortran, using FORM to determine the reliability index $\beta$ (Ref. Appendix A), where

$P_{f}=\Phi(-\beta)$

Five cases are considered: the critical crack depth assumed to be: (1) equal to $B$; (2) equal to $0.5 B$; (3) equal to $0.2 B$; (4) associated with fracture applying the lower bound solution (lb); (5) associated with fracture applying the upper bound solution (ub). The value of the crack depth at fracture in the 4th case appears to be approximately $a_{f} \approx 0.6 \mathrm{~B}$. In all cases, the Paris law parameters $A$ 


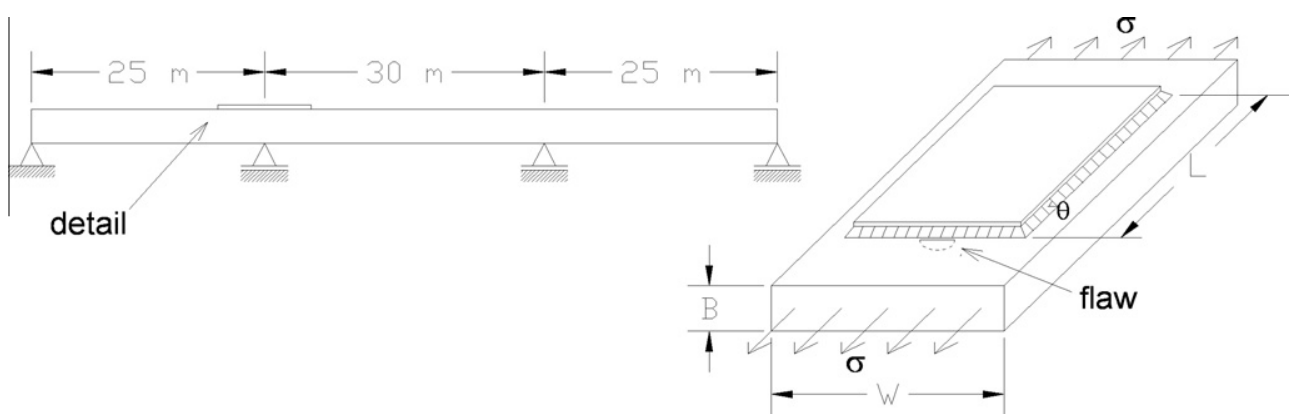

Fig. 5. Geometry considered in the example.

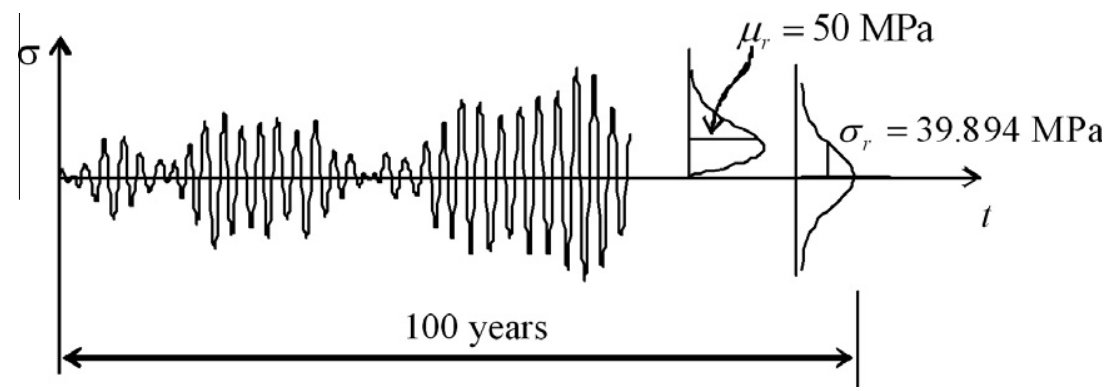

Fig. 6. Fatigue load model.

Table 2

Values for case-specific parameters considered in the example (units: $\mathrm{mm}, \mathrm{N},{ }^{\circ} \mathrm{C}$ ).

\begin{tabular}{|c|c|c|}
\hline Parameter & & Value \\
\hline$B$ & Plate thickness & 40 \\
\hline$W$ & Plate width & 800 \\
\hline$L$ & Node length & 2000 \\
\hline$p$ & Thickness exponent & 0.80 \\
\hline$\mu_{r}$ & Mean value of the Gaussian stress process & 50 \\
\hline$\sigma_{r}$ & Standard deviation of Gaussian stress process & 40 \\
\hline \multirow[t]{2}{*}{$\sigma_{\text {perm }}$} & Permanent stress & 100 \\
\hline & Steel grade & S355 \\
\hline$T_{27 \mathrm{~J}}$ & Temperature corresponding to a CVN of $27 \mathrm{~J}$ & -50 \\
\hline$\mu_{T}$ & Mean value of the operating temperature (Gauss distribution) & 10 \\
\hline$\sigma_{T}$ & Standard deviation of the operating temperature (Gauss distribution) & 8 \\
\hline$V_{\text {Cload }}$ & Coefficient of variation of the uncertainty with respect to the load model & 0.10 \\
\hline
\end{tabular}
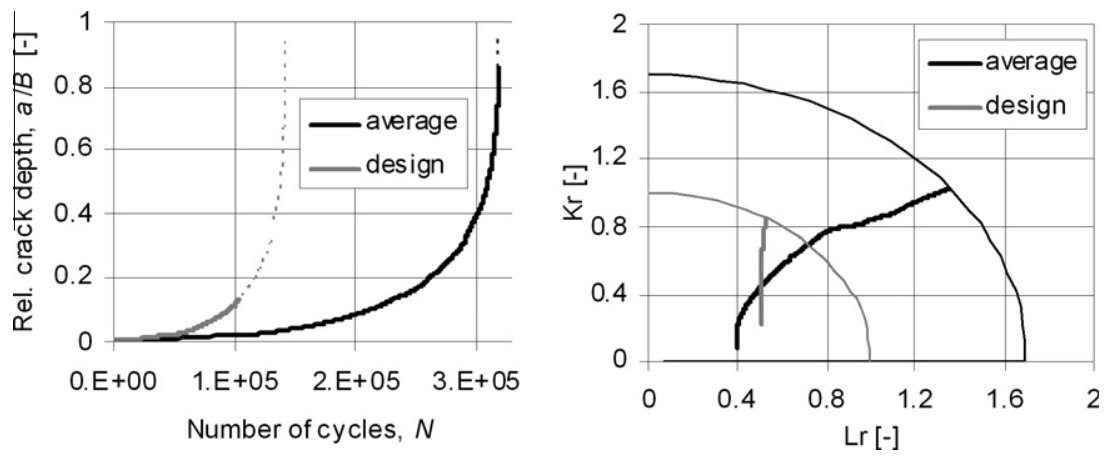

Fig. 7. Result of the deterministic calculation (a) Crack growth, (b) Failure assessment diagram.

and model uncertainties $C$ are considered to be fully correlated in depth and in width direction. Fig. 8 presents the resulting value of $\beta$ as a function of the number of cycles.

The figure indicates that the lower bound and the upper bound solutions of the fracture criterion give the same failure probability. A larger parametric study with other values for $T_{27}, T, \sigma_{r}$ and $\sigma_{\text {perm }}$ has been carried out. In all cases, the difference in $\beta$ between the lower and upper bound solutions was negligible. Hence, it is sufficient to only consider the lower bound solution - which is considerably easier to program than the upper bound solution.

Further, the figure shows that the failure criterion has almost no effect on $\beta$. This is attributed to the progressive crack growth 


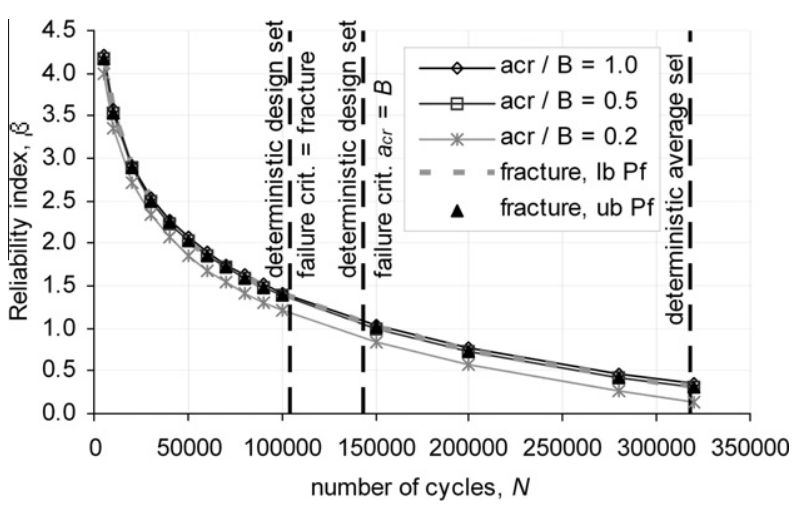

Fig. 8. $\beta$ as a function of $N$ for various failure criteria.

(Fig. 7) where the number of cycles between $a=0.2 B$ and $a=B$ is only $20 \%$ of the total number of cycles between $a=a_{0}$ and $a=0.2$ $B$. Based on the parametric study with other values for $T_{27}, T, \Delta \sigma$ and $\sigma_{\text {perm }}$, the relative insensitivity to the failure criterion appears to be typical for the entire fatigue life of a welded joint, provided that the critical crack depth at fracture is larger than approximately $0.2 B$. This is generally the case if the following conditions are satisfied:

- The fluctuating stress is relatively large (we considered cases with $\sigma_{r} \geqslant 10 \mathrm{~N} / \mathrm{mm}^{2}$ ).

- The permanent stress is not larger than half the yield stress, in agreement with the findings in [15].

- The temperature difference between the minimum operating temperature $T_{\min }$ and the Charpy transition temperature at $27 \mathrm{~J}$ is sufficiently large, so that the structure is in the transition range or upper-shelf range. The required temperature difference is: $\left(T_{d}-T_{27 \mathrm{~J}}\right) \geqslant 40^{\circ} \mathrm{C}$ for $40 \mathrm{~mm}<B \leqslant 100 \mathrm{~mm}$ and $\left(T_{d}-T_{27 \mathrm{~J}}\right) \geqslant 20^{\circ} \mathrm{C}$ for $B \leqslant 40 \mathrm{~mm}$.

These conditions are satisfied for most civil engineering structures. For these conditions, and for these conditions only, a reasonable estimate of the failure probability is obtained by considering the criterion $a_{c r}=B$. If these conditions are not met, the fracture criterion needs to be considered in determining the failure probability.

The FORM sensitivity factors $\alpha$ resulting from the analysis indicate the relative importance of the random variables at the design point (Ref. Appendix A). The crack growth parameter $A$ and the model uncertainties $C$ appear to be the most important variables. The sensitivity factors for $A, C_{\text {load }}, C_{\text {glob }}, C_{s c f}$ and $C_{\text {sif }}$ are $\alpha=0.5,0.3$, $0.3,0.5$ and 0.5 , respectively.

The relationship between $\beta$ and $N$ in Fig. 8 can be compared with the number of cycles to failure according to the deterministic sets of random variables (vertical lines in Fig. 8) in order to determine the failure probability for these deterministic sets. As an example, the deterministic analyses with the average variables gives a failure probability of $P_{f}=0.38$. The reason that the average set does not result in $P_{f}=0.5$ is due to the fact that not all random variables have a Gauss distribution.

Partial factors are introduced which allow the designer to assess the structure with the deterministic model while meeting the required reliability index. The partial factors are seen as reflecting both the level of uncertainty in a calculation as well as the level of consequences of failure. The procedure followed in this article allows for calibrating partial factors. The partial factor for fatigue $\gamma_{\text {fat }}$ is derived with which Eq. (3) should be multiplied:

$\Delta K_{a}=\gamma_{f a t} \cdot\left(\Delta \sigma_{m} Y_{m a}+\Delta \sigma_{b} Y_{b a}\right) \sqrt{\pi a}$
$\Delta K_{c}=\gamma_{f a t} \cdot\left(\Delta \sigma_{m} Y_{m c}+\Delta \sigma_{b} Y_{b c}\right) \sqrt{\pi a}$
Note that separate partial factors are usually defined for the load and for the resistance side. For simplicity, only one overall partial factor $\gamma_{f a t}$ is used here which covers scatter in the load and in the resistance. The values for the partial factor in Eq. (29) are determined with the deterministic model using the 'design set' of variables and applying the failure criterion $a_{c r}=B$. The number of load cycles to failure for the case $\gamma_{f a t}=1.0$ according to this deterministic model is $N_{c r}=1.4 \times 10^{5}$ (Fig. 7). Fig. 8 indicates that the corresponding reliability index is equal to $\beta=1.1$. A deterministic calculation can be made with a certain value for $\gamma_{f a t}$, resulting in a certain value for $N_{c r}$. Subsequently, the reliability index corresponding with this value can be subtracted from Fig. 8. This allows for establishing the partial factor for a certain required reliability index. As an example, analyses with the model for the geometry and loading parameters in this chapter result in $\gamma_{f a t}=1.2,2.0,2.6$ and 3.1 for $\beta=1.5,3.1,3.8$ and 4.3 , respectively.

\section{Partial factors for fatigue LEFM}

Failure probabilities and partial factors for fatigue of welded details are derived with the procedure described in Section 4.2. The applied failure criterion is the attainment of a through-thickness crack $a_{c r}=B$. The values for $\gamma_{f a t}$ should be applied according to Eq. (29). The values for $\gamma_{f a t}$ are only valid for an initial weld defect in an as-welded structure - with distributions for the defect size according to Table 1 - and design values for all variables. In total, 48 combinations of geometries and load spectra are considered according to Table 3 and Fig. 9. The combinations considered are expected to cover most welded details in civil engineering structures.

For structures in reliability class 2, the European standard EN 1990 recommends a target value of $\beta$ for the entire fatigue life ranging from 1.5 to 3.8 , depending on the degree of inspectability, repairability and damage tolerance.

The number of cycles to failure varies considerably between the considered cases. However, the variation in partial factors for all combinations of geometry and load spectrum appears to be small: $V$ is between 0.01 and 0.04 . This means that the partial factor is

Table 3

Geometric variables considered for deriving partial factors for fatigue LEFM.

\begin{tabular}{ll}
\hline Variable & Values \\
\hline$B$ & $10 \mathrm{~mm}, 25 \mathrm{~mm}, 40 \mathrm{~mm}$ \\
$W$ & $800 \mathrm{~mm}$ \\
$L$ & $25 \mathrm{~mm}, 40 \mathrm{~mm}, 60 \mathrm{~mm}, 2000 \mathrm{~mm}$ \\
$\theta$ & $45^{\circ}$ \\
\hline
\end{tabular}

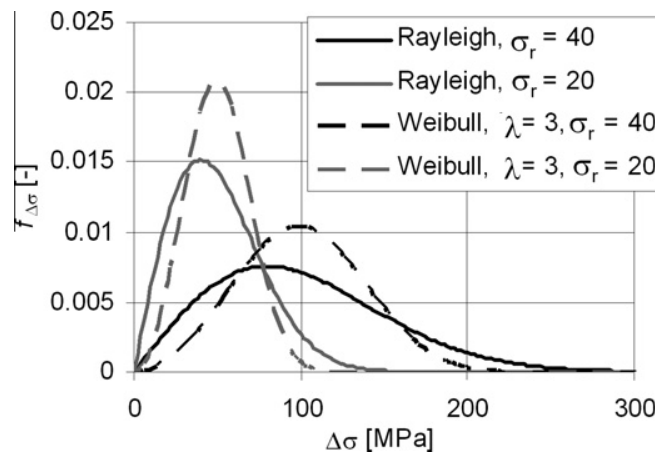

Fig. 9. Probability density functions of load spectra considered for deriving partial factors for fatigue LEFM 
Table 4

Partial factors $\gamma_{f a t}$ for fatigue LEFM for as-welded structures (distributions according to Table 1, deterministic values according to Table 3 ) as a function of the reliability index for the entire fatigue life.

\begin{tabular}{|c|c|c|c|c|c|c|c|}
\hline & & & $\beta$ & 1.5 & 3.1 & 3.8 & 4.3 \\
\hline & & & $P_{f}$ & $7 \times 10^{-2}$ & $10^{-3}$ & $7 \times 10^{-5}$ & $10^{-5}$ \\
\hline$V_{\text {Cload }}$ & $V_{\text {Cglob }}$ & $V_{C s c f}$ & $V_{C s i f}$ & & & & \\
\hline 0.0 & 0.1 & 0.2 & 0.2 & 1.1 & 2.0 & 2.6 & 3.1 \\
\hline 0.0 & 0.1 & 0.2 & 0.07 & 1.0 & 1.7 & 2.1 & 2.5 \\
\hline 0.0 & 0.1 & 0.1 & 0.07 & 1.0 & 1.5 & 1.8 & 2.0 \\
\hline 0.1 & 0.1 & 0.2 & 0.2 & 1.1 & 2.1 & 2.7 & 3.3 \\
\hline 0.1 & 0.1 & 0.2 & 0.07 & 1.1 & 1.8 & 2.3 & 2.7 \\
\hline 0.1 & 0.1 & 0.1 & 0.07 & 1.0 & 1.5 & 1.9 & 2.2 \\
\hline 0.2 & 0.1 & 0.2 & 0.2 & 1.2 & 2.3 & 3.1 & 3.9 \\
\hline 0.2 & 0.1 & 0.2 & 0.07 & 1.2 & 2.1 & 2.7 & 3.2 \\
\hline 0.2 & 0.1 & 0.1 & 0.07 & 1.1 & 1.9 & 2.3 & 2.7 \\
\hline
\end{tabular}

relatively independent of the geometry and load spectrum. Since the considered geometries and load spectra differ significantly, it is expected that the derived partial factors are generally applicable. The resulting partial factors as a function of $\beta$ are provided in Table 4 , for various sets of coefficients of variations for the model uncertainties. These factors serve as an example: In the authors' view, the main contribution of this paper is the probabilistic model that allows for deriving partial factors. The model can also used be to determine separate partial factors for the load and resistance side, to determine the inspection interval, and to determine the partial factors in case of the residual fatigue life of structures after inspection. In the latter case, the average value and coefficient of variation of the initial crack dimensions $a_{o}$ and $c_{o}$ should be based on the probability of detection curve of the inspection technique. Note that the failure criterion - either $a_{c r}=B$ or fracture - may influence the residual life in that case and should thus be incorporated into the model as shown in Sections 3 and 4.

\section{Conclusions}

This paper presents a probabilistic linear elastic fracture mechanics model to be used for fatigue loaded civil engineering structures. The application of the model on a bridge detail is presented, and partial factors are derived. The following conclusions result from the work:

1. Model uncertainty factors appear to be important in the assessment of the failure probability. Thus, it is important to account for model uncertainties. In addition, the design life can be increased if it can be demonstrated that the model uncertainties are smaller than assumed in this paper.

2. A lower bound and an upper bound solution are provided for the failure probability in case of fatigue crack growth followed by fracture. These solutions give almost equal failure probabilities for the distribution functions of variables considered in this paper. Hence, it is sufficient to only consider the lower bound solution - which is considerably easier to program.

3. The failure probability is relatively insensitive to the failure criterion ( $a_{c r}=B$ or $a_{c r}$ is associated with fracture) for the entire fatigue life of most civil engineering structures. This justifies the fact that the fracture criterion is not explicitly accounted for in standards based on $S-N$ curves.

4. For civil engineering structures, a partial factor $\geqslant 1.0$ needs to be applied in order to meet the required reliability for fatigue of a civil engineering structure for all values of the reliability index $\beta$ recommended in EN 1990.

5. Partial factors for fatigue LEFM are derived for various values of $\beta$. These partial factors appear to be insensitive to the detail geometry and the load spectrum.

\section{Appendix A. The system analysis by Hohenbichler and Rackwitz [22]}

In the First Order Reliability Method (FORM), the limit state function is linearised in the design point. This design point is the point on the curve $g(X)=0$ with the highest probability density. The design point is determined using a numerical iteration procedure. FORM uses a set of independent standard Gauss variables $u$. The physical variables $X$ are obtained by transformation

$X=\mu_{X}+u \sigma_{X}$

$F_{X}(x)=\Phi(u)$

The linearised limit state function can be written as

$g_{L}=B+A_{1} u_{1}+A_{2} u_{2}+\cdots$

Since $\mu\left(g_{L}\right)=B$ and $\sigma\left(g_{L}\right)=\sqrt{\sum_{i} A_{i}^{2}}$, the reliability index and failure probability can be obtained through

$\beta=\frac{\mu\left(g_{L}\right)}{\sigma\left(g_{L}\right)}=\frac{B}{\sqrt{\sum_{i} A_{i}^{2}}}$

$P(g<0) \approx P\left(g_{L}<0\right)=\Phi(-\beta)$

Dividing $g_{L}$ by $\sqrt{\sum_{i} A_{i}^{2}}$ gives

$g_{L}^{*}=\beta+\alpha_{1} u_{1}+\alpha_{2} u_{2}+\cdots$

where $\alpha_{i}=\frac{A_{i}}{\sqrt{\sum_{i} A_{i}^{2}}}$.

The design point values for the random variables are

$u_{d, i}=-\alpha_{i} \beta$

$X_{d, i}=F^{-1} \Phi\left(u_{d, i}\right)=F^{-1} \Phi\left(-\alpha_{i} \beta\right)$

The method of Hohenbichler is used in this paper to determine the failure probability of a system consisting of two limit state functions. In the case of a series system

$P(F)=P\left\{g_{a}<0 \cup g_{b}<0\right\}$

where we assume that $g_{a}$ and $g_{b}$ are Gauss distributed. The failure probability is rewritten according to

$$
\begin{aligned}
P(F) & =P\left\{g_{a}<0\right\}+P\left\{g_{b}<0\right\}-P\left\{g_{a}<0\right\} \cdot P\left\{g_{b}<0 \mid g_{a}\right. \\
& <0\}
\end{aligned}
$$

For the derivation below, $g_{a}$ and $g_{b}$ should be selected such that $\beta_{a}>\beta_{b}$. The problem is reduced to determining the conditional probability $P\left\{g_{b}<0 \mid g_{a}<0\right\}$. This conditional probability depends on $\beta_{a}, \beta_{b}$ and correlation coefficient $\rho_{a b}$.

$\rho_{a b}=\sum_{i=1}^{n} \alpha_{a i} \cdot \alpha_{b i} \cdot \rho_{a b i}$

where $\alpha_{a i}$ is $\alpha$ of $X_{i}$ in $g_{a} ; \alpha_{b i}$ is $\alpha$ of $X_{i}$ in $g_{b}$ and $\rho_{a b i}$ is the correlation of variable $X_{i}$ in element $g_{a}$ and the same variable in element $g_{b}$. Values for $\beta_{a}, \beta_{b}, \alpha_{a i}, \alpha_{b i}$ follow from the FORM analysis. Limit state functions $g_{a}$ and $g_{b}$ are now written as

$g_{a}=\beta_{a}-u$

$g_{b}=\beta_{b}-v$

where $u$ and $v$ are standard Gauss distributed. Since $\beta_{a}$ and $\beta_{b}$ are constant: $\rho(u v)=\rho_{a b}$. Let us replace the dependent Gauss variables $u$ and $v$ by independent Gauss variables $u$ and $w$. Limit state function $g_{b}$ can then be written as

$g_{b}=\beta_{b}-\rho_{a b} u-w \sqrt{1-\rho_{a b}^{2}}$ 
The conditional probability is written as

$$
\begin{aligned}
P\left\{g_{b}\right. & \left.<0 \mid g_{a}<0\right\} \\
& =P\left\{\beta_{b}-\rho_{a b} u-w \sqrt{1-\rho_{a b}^{2}}<0 \mid \beta_{a}-u<0\right\}
\end{aligned}
$$

Hohenbichler proposed replacing this conditional probability by the following unconditional probability

$$
\begin{aligned}
P\left\{g_{b}\right. & \left.<0 \mid g_{a}<0\right\}=P\left(g_{b}^{\prime}<0\right) \\
& =P\left\{\beta_{b}-\rho_{a b} u^{\prime}-w \sqrt{1-\rho_{a b}^{2}}<0\right\}
\end{aligned}
$$

where $u^{\prime}$ is the original variable $u$ in which is considered that $u>\beta_{a}$.

$u^{\prime}=\Phi^{-1}\{1-p \cdot \Phi(u)\}$

$p=P\left\{u>\beta_{1}\right\}$

The limit state function $g_{b}^{\prime}$ can now be written as:

$g_{b}^{\prime}=\beta_{b}-\rho \cdot \Phi^{-1}\{1-p \cdot \Phi(u)\}-w \sqrt{1-\rho_{a b}^{2}}$

The failure probability $P\left\{g_{b}^{\prime}<0\right\}$ can be determined using the standard FORM.

In this paper, we have used the method of Hohenbichler to determine the failure probability in the case of a series system of more than two elements. As an example, in the case of a series system with three elements $g_{a}, g_{b}$ and $g_{c}$, the following steps are carried out:

- Determine the combined failure probability of the first two elements $g_{a}$ and $g_{b}$ using the procedure of Hohenbichler described above.

- Determine the values for $\alpha_{i}$ and $\beta$ of the combined limit state function.

- Use the procedure of Hohenbichler to determine the combined failure probability of the two elements $\left(g_{a}\right.$ and $\left.g_{b}\right)$ and $g_{c}$.

\section{References}

[1] BS 7910. Guide to methods for assessing the acceptability of cracks in metallic structures. London: BSI; 2005.

[2] Hobbacher A. IIW recommendations for fatigue design of welded joints and components XIII-1965-03/XV-1127-03. IIW; 2006.
[3] Burkedin FM, Hamour W. Partial safety factors for SINTAP procedure. Offshore technology report 2000 020. Oxon: HSE; 2002.

[4] Burkedin FM, Hamour W. Calibration of partial safety factors for use with BS 7910. UMIST CIV/SAG/98/2. Manchester; 1998.

[5] EN 1993-1-9. Eurocode 3: Design of steel structures - Part 1-9: Fatigue. Brussels: CEN; 2006.

[6] EN 1993-1-1. Eurocode 3: Design of steel structures - Part 1-10: Material toughness and through-thickness properties. Brussels: CEN; 2005.

[7] Ishikawa H, Tsurui A, Tanaka H, Ishikawa $H$. Reliability assessment of structures based upon probabilistic fracture mechanics. Probabilist Eng Mech 1993;8:43-56.

[8] Yazdani N, Albrecht P. Probabilistic fracture mechanics application to highway bridges. Eng Fract Mech 1990;37:969-88.

[9] Chryssanthopoulos MK, Righiniotis TD. Fatigue reliability of welded steel structures. J Constr Steel Res 2006;62:1199-209.

[10] Lukić M, Cremona C. Probabilistic assessment of welded joints versus fatigue and fracture. J Struct Eng - ASCE 2001;127:211-8.

[11] O'Conner A, O'Brian EJ. Traffic load modelling and factors influencing the accuracy of predicted extremes. Can J Civil Eng 2005;32:270-8.

[12] James G. Analysis of traffic load effects on railway bridges. Dissertation. Stockholm: Royal Institute of Technology; 2003.

[13] Holmes JD. Wind loading of structures. 2nd ed. Abingdon: Taylor and Francis; 2001.

[14] Soares CG, Moan T. Model uncertainty in the long-term distribution of waveinduced bending moments for fatigue design of ship structures. Mar Struct 1991:4:295-315.

[15] Sedlacek G et al. Design of steel structures. Part 2 - Bridges, for chapter 3 materials, choice of steel material to avoid brittle fracture - background documentation to Eurocode 3. Aachen: Rheinische-Westfael Technische Hochschule; 1997.

[16] Murakami Y. Stress intensity factors handbook. Oxford: Pergamon Press; 1987.

[17] Paris PC, Erdogan F. A critical analysis of crack propagation laws. J Basic Eng Trans ASME 1963;85:528-34.

[18] Dijkstra OD. A fracture mechanics approach to the assessment of the remaining fatigue life of defective welded joints. In: Proceedings of IABSE 1990 Lausanne. Zürich: IABSE; 1991. p. 1-12.

[19] Dowling NE. Fatigue failure prediction for complicated stress-strain histories. J Mater 1972;7:71-87.

[20] Zhao W, Baker MJ. On the probability density function of rainflow stress ranges for stationary Gaussian processes. Int J Fatigue 1992;14:121-35.

[21] Wallin K. The scatter in KIC results. Eng Fract Mech 1984;19:1085-93.

[22] Hohenbichler M, Rackwitz R. First-order concepts in system reliability. Struct Saf 1983;1:177-88.

[23] Austen I. Measurement of fatigue crack threshold values for use in design. SH/ EN/9708/2/83/B. London: British Steel Corporation; 1983.

[24] Kountouris IS, Baker MJ. The reliability of non-destructive examination of welded joints. CESLIC Report OR7; 1989.

[25] Kountouris IS, Baker MJ. Defect assessment: analysis of the dimensions of defects detected by ultrasonic inspection in an offshore structure. CESLIC Report OR8; 1989.

[26] JCSS probabilistic model code. Part 3: Material properties. JCCS; 2000. <http:// www.jcss.byg.dtu.dk/>.

[27] Hobbacher A. Stress intensity factors of welded joints. Eng Fract Mech 1993;46:173-82. 